\title{
Correspondence
}

\section{Aviemore meeting and the gently battered child}

Sir,

In Aviemore in April 1982, I presented to the British Paediatric Association's meeting the concept of the 'gently battered child'. The numerical results quoted at that time have since been published as part of a paper in this journal. ${ }^{1}$ Because of the nature of the concept, the paediatricians present were asked by means of notices on the screen and Chairman's comments to treat this session and other communications in that session as confidential.

About a month ago, the Editor of World Medicine telephoned me at home to say that he had received an article from a paediatrician who had been present at the Aviemore meeting and that he intended to publish it. The name of the paediatrician was refused me. Several sentences from the article were read to me over the telephone and I protested that the statements were misleading, and that such a report would cause great and unnecessary distress to many parents and other people. I tried to put the situation in perspective.

I heard nothing more until I was told by a friend, of an article in World Medicine. The information was presented in such a way that people have construed that the whole article had arisen from an interview with me. The article was accompanied by an evocative drawing and was unsigned. That article was taken up by other papers and while it perhaps caused only transient annoyance to me, it resulted in great distress to many innocent cot death parents and those who attempt to help them.

Most of us are well aware of the extent that the press can distort information for effect, but members should also be aware that just as in hospital wards where there are 'moles' prepared to report on the treatment of patients, so there appear to be equivalent people among us prepared to report to the non-specific medical press things presented in confidential plenary sessions of the British Paediatric Association.

\section{Reference}

1 Taylor E M, Emery J L. Two-year study of the causes of postperinatal deaths classified in terms of preventability. Arch Dis Child 1982; 57: 668-73.

J L EMERY Wolfson Unit, Department of Paediatrics, University of Sheffield, 312 Fulwood Road, Sheffield S10 3BN

Two-year study of the causes of postperinatal deaths classified in terms of preventability

Sir,

This paper $^{1}$ contains serious allegations against parents and gives data on explanations for sudden infant death syndrome (SIDS) without scientific evidence and which are at variance with the majority of epidemiological research.

The authors' evidence for 'gentle battering' is pure conjecture. If this diagnosis was seriously considered surely an inquest after a forensic post-mortem examination should have been held.

The allocation of deaths from the SIDS category to a preventable or explainable category has not been carried out in a scientific way. Moreover the facts presented are misleading. Thus, on page 664 in category $\mathrm{B}$ where there were 15 home deaths, only 8 were discussed; are the other 7 cases the 'minor disease, metabolic upset'category B, group 4 in Table 2 ? In the Discussion a statement was made that '. . . there are either 7 or 4 (unexplained, unexpected deaths in Sheffield) depending on whether interpretation is made purely on postmortem findings or on a complete study including the psychosocial background'. It is impossible to determine from reading this report the origin of these figures.

Throughout this paper the authors apportion blame for many infant deaths either to poor care by parents or to infanticide. Their allegations are illustrated by case histories which contain suspicions of the type that comprise malicious gossip rather than judicial or scientific evidence. A control group of infants from families with psychosocial problems who do not die will need to be examined before any meaningful conclusions can be reached on the relationship between these problems and SIDS. This unfortunate report will undoubtedly result in much suffering for the parents of infants who have or who will in the future suffer SIDS. There is now a need to counter these allegations by the publication, as soon as possible, of studies carried out by other paediatric pathologists.

\section{Reference}

1 Taylor E M, Emery J L. Two-year study of the causes of postperinatal deaths classified in terms of preventability. Arch Dis Child 1982; 57: 668-73.

D P SouthaLL Cardiothoracic Institute, Fulham Road, London SW3 6HP

\section{Are facial bruises in babies ever accidental?}

Sir,

In our experience cot-bound babies in hospital who tumble against the metal bars do not bruise themselves. Moreover, bruising of any sort in babies under age 1 year is rarely seen in our clinics, although such minor accidents in the home must be fairly common. Glib parental explanations such as, 'He fell against the cot bars', or 'He fell over on to his plastic toy' are often accepted in 
the case of a bruise on the side of the forehead, cheeks, or chin, even in at-risk infants. It is not uncommon for the truth (that they are really finger bruises) to be admitted after a Care Order has been obtained after more severe injury.

In older children, by contrast, bruises, even those resembling finger tip bruises, are common and can be accepted as accidental, as shown by $\mathrm{Keen}^{1}$ in his careful study of 3- and 4-year-old children.

In view of our observations, it was decided to assess the incidence of facial and other bruises in a random sample of babies under age 1 year. Altogether 620 examinations of naked babies who were attending either a local authority health clinic, or a hospital follow-up clinic were made.

Bruises were seen on 6 babies only.

Case 1: Age 10 months. Already walking, showed 3 typical small (less than $15 \mathrm{~mm}$ ) toddler shin bruises on each leg.

Case 2: Age $11 \frac{1}{2}$ months. Already walking, showed one typical small toddler shin bruise and a swollen $15 \mathrm{~mm}$ central forehead bruise.

Case 3: Age 10 months. Actively crawling, showed a $5 \mathrm{~mm}$ bruise on the outer aspect of the right arm and a small scratch on the outside of the right thigh.

Case 4: Age 10 months. A crawling baby who was able to climb upstairs, showed a $10 \times 10 \mathrm{~mm}$ bruise on the point of the chin, caused by slipping against the coffee table.

Case 5: Age 9 months. An active, crawling, climbing baby showed a tiny central forehead bruise, caused by a fall from a toy tractor.

Case 6: Age 3 months. Had a $5 \times 10 \mathrm{~mm}$ bruise under the right eye, due to falling on the telephone.

It is interesting that in our study the bruises, with one exception, were seen in babies of at least 9 months, who were already actively crawling or walking. The facial bruises in these children were on the central forehead, or point of the chin and showed, or had shown, swelling due to 'hard, contact' injury. They were quite dissimilar to the finger tip and thumb bruises seen in child abuse and so clearly described by Hall. ${ }^{2}$

The exception, Case 6, caused us anxiety, especially as an older sibling had also had worrying incidents. It was considered that the problem was due to an unacceptable level of carelessness and the situation was closely monitored by the health visitor. When the family moved away a few months later, the new health visitor was alerted.

Of the 5 other cases, 4 bruises were on shins and only 1 on an arm (Case 3 ) and this was accepted as accidental.

This study shows that facial bruising is rare in infancy. It also suggests that, if genuinely accidental bruises do occur in this age group, they are different from finger bruises. We submit that health workers and social workers should not accept an alternative explanation for bruises on the sides of the forehead, cheeks, and jaws that look like finger bruises. We consider it unlikely that a baby failing from sitting against the cot bars, or rolling over on to a toy will sustain such a bruise.

\section{References}

1 Keen J H. Letter: Normal bruises in preschool children. Arch Dis Child 1981; 56: 75.

2 Hall M H. The diagnosis and early management of non-accidental injuries in children. The Police Surgeon 1974; No 6: 17.

$$
\begin{array}{r}
\text { PATRICIA E MORTIMER } \\
\text { Chase Farm Hospital, } \\
\text { The Ridgeway, } \\
\text { Enfield EN2 8JL, } \\
\text { Middlesex } \\
\text { MYRA FREEMAN } \\
\text { Camden and Islington Area Health Authority, } \\
\text { Insurance House, Insurance Street, } \\
\text { London WCIX } 0 J B
\end{array}
$$

\section{Total colonoscopy in children}

Sir,

We read the report of Williams et al. ${ }^{1}$ with interest and offer the following comments.

Cleansing enemas (phosphate, tap water, saline) were used in all patients as an adjunctive bowel preparation for colonoscopy. Enemas may cause mucosal hyperaemia, petechiae, mucosal mucus depletion, and inflammatory changes in rectal mucosa-that is, endoscopic and histological changes which could be confused with those of inflammatory bowel disease. Since many patients with inflammatory bowel disease will have normal rectal mucosa endoscopically but be diagnosed on rectal histology alone, ${ }^{2}$ avoidance of confusing artefact on histology is vital. ${ }^{3}$

In addition, cold mannitol was used to prepare some patients. Since the report of a fatal colonic explosion during polypectomy attributed in part to mannitol degradation in the colon, ${ }^{4}$ the use of mannitol as a bowel preparation has been eschewed.

Regarding sedation, we have had to use larger doses than the $50 \mathrm{mg}$ pethidine and $10 \mathrm{mg}$ diazepam quoted in order to achieve good analgesia and amnesia in children over age 8 years. We individualise dosage and often use $3-4 \mathrm{mg} / \mathrm{kg}$ pethidine intravenously (in addition to intravenous diazepam) to ensure a non-traumatic procedure for the child. We find the use of these doses to be safe if given slowly while the patient is closely monitored, and paediatricians and nursing staff are present in an endoscopy room well equipped for potential resuscitation of children. Need for naloxone or oxygen is rare.

Finally, we disagree that colonoscopy or polypectomy needs referral to an adult gastroenterologist. With the growth of paediatric gastroenterology as a separate but allied discipline, there should be adequate paediatric expertise to perform these procedures completely. All of our approximately 130 colonoscopies and polypectomies during the last 10 years have been performed by our paediatric gastroenterology staff or fellows in training under supervision.

We feel that children should be seen, instrumented, and followed by paediatricians who are, after all, in the business of working with children and families.

\section{References}

1 Williams C B, Laage N J, Campbell C A, er al. Total colonoscopy in children. Arch Dis Child 1982; 57: 49-53.

2 Vanderhoof J A, Ament M E. Proctosigmoidoscopy and rectal biopsy in infants and children. $J$ Pediatr 1976; 89: 911-5. 